\title{
ОЦЕНКА ПРИВЛЕКАТЕЛЬНОСТИ МАКРОЭКОНОМИЧЕСКОГО СУБЪЕКТА ДЛЯ РЕАЛИЗАЦИИ ИННОВАЦИОННЫХ ПРОЕКТОВ ГОСУДАРСТВЕННО-ЧАСТНОГО ПАРТНЕРСТВА
}

\section{ASSESSMENT OF ATTRACTIVENESS \\ OF A MACROECONOMIC SUBJECT FOR IMPLEMENTATION OF INNOVATIVE PROJECTS OF PUBLIC-PRIVATE PARTNERSHIP}

\section{Ujakov \\ E. Nayanov \\ O. Ignatyeva}

Summary: The article discusses tools for assessing the attractiveness of regions in the implementation of public-private partnerships. A detailed analysis of the criteria that will help investors determine the volume and degree of implementation of projects, as well as build long-term forecasts and plans for their implementation is presented.

Keywords: public-private partnership, macroeconomic indicators, comprehensive risk analysis, investment attractiveness, efficiency assessment.
Ужаков Демьян

ФГБОУ ВО «Московский политехнический университет» mister-231996@mail.ru

Наянов Евгений Александрович старший преподаватель, ФГБОУ ВО «Московский политехнический университет» e.a.nayanov@mospolytech.ru

Игнатьева Ольга Валерьевна

Доцент, ФГБОУ ВО «Московский политехнический университет»

Oignatyeva@mail.ru

Аннотация: В статье рассмотрены инструменты оценки привлекательности регионов в области реализации государственно-частного партнерства. Представлен подробный анализ критериев, которые помогут инвесторам определять объемы и степень внедрения проектов, а так же строить долгосрочные прогнозы и планы по их исполнению.

Ключевые слова: государственно-частное партнерство, макроэкономические показатели, комплексный анализ рисков, инвестиционная привлекательности, оценка эффективности.

нах мира. Передовыми странами являются Канада, США, Индия, где данные проекты зарекомендовали себя с наилучшей точки зрения, так как обладали рядом преимуществ (табл. 1)

Таблица 1

Целью ГЧП с экономической точки зрения является привлечение и стимулирование частных инвестиций в производство, а так же сокращение доли участия государства в финансовом обороте.

Проанализировав, соответствующую литературу, можно сделать вывод, что ГЧП-проекты в Российской Федерации могут осуществляться в следующих формах (рис. 1)

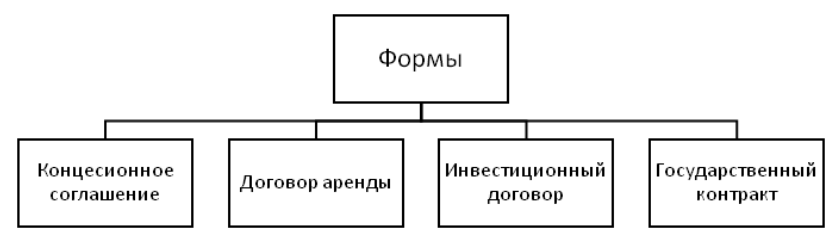

Рис. 1. Формы ГЧП-проектов

Опыт применения долгосрочного инвестирования на основании ГЧП зарекомендовал себя во многих стра-
Преимущества ГЧП

\begin{tabular}{|c|c|}
\hline \multicolumn{2}{|c|}{ Преимущества ГЧП } \\
\hline Публичная сторона & Частная сторона \\
\hline $\begin{array}{l}\text { Привлечение инвестора, позволя- } \\
\text { ет реализовать инфраструктурные } \\
\text { проекта без увеличения долговой } \\
\text { нагрузки }\end{array}$ & $\begin{array}{l}\text { Взаимодействие с публичной } \\
\text { стороной на основе долгосрочного } \\
\text { соглашения }\end{array}$ \\
\hline $\begin{array}{l}\text { Объединение этапов (проектиро- } \\
\text { вание, строительство, эксплуата- } \\
\text { ция) }\end{array}$ & $\begin{array}{l}\text { Получение участков, без осущест- } \\
\text { вления торгов }\end{array}$ \\
\hline Приобретение услуги & $\begin{array}{l}\text { Получение дополнительных } \\
\text { гарантий }\end{array}$ \\
\hline \multicolumn{2}{|c|}{ Передача рисков } \\
\hline $\begin{array}{l}\text { Снижение роли государства в } \\
\text { экономике }\end{array}$ & $\begin{array}{l}\text { Закрепление в областях с высо- } \\
\text { ким присутствием государства в } \\
\text { экономике }\end{array}$ \\
\hline
\end{tabular}

Реализация проектов на основе привлечения государства и частного бизнеса позволит вывести страну на 
должный международный уровень. Предлагаемая методика по реализации ГЧП в регионе представлена на рисунке 2.

На первой этапе реализации проводится анализ фе- дерального и регионального законодательства. Второй этап начинается с оценки наиболее значимых макроэкономических показателей. Третий - оценка рисков по проекту на разных его стадиях. Четвертый - оценка качества человеческого капитала. Теперь рассмотрим под-

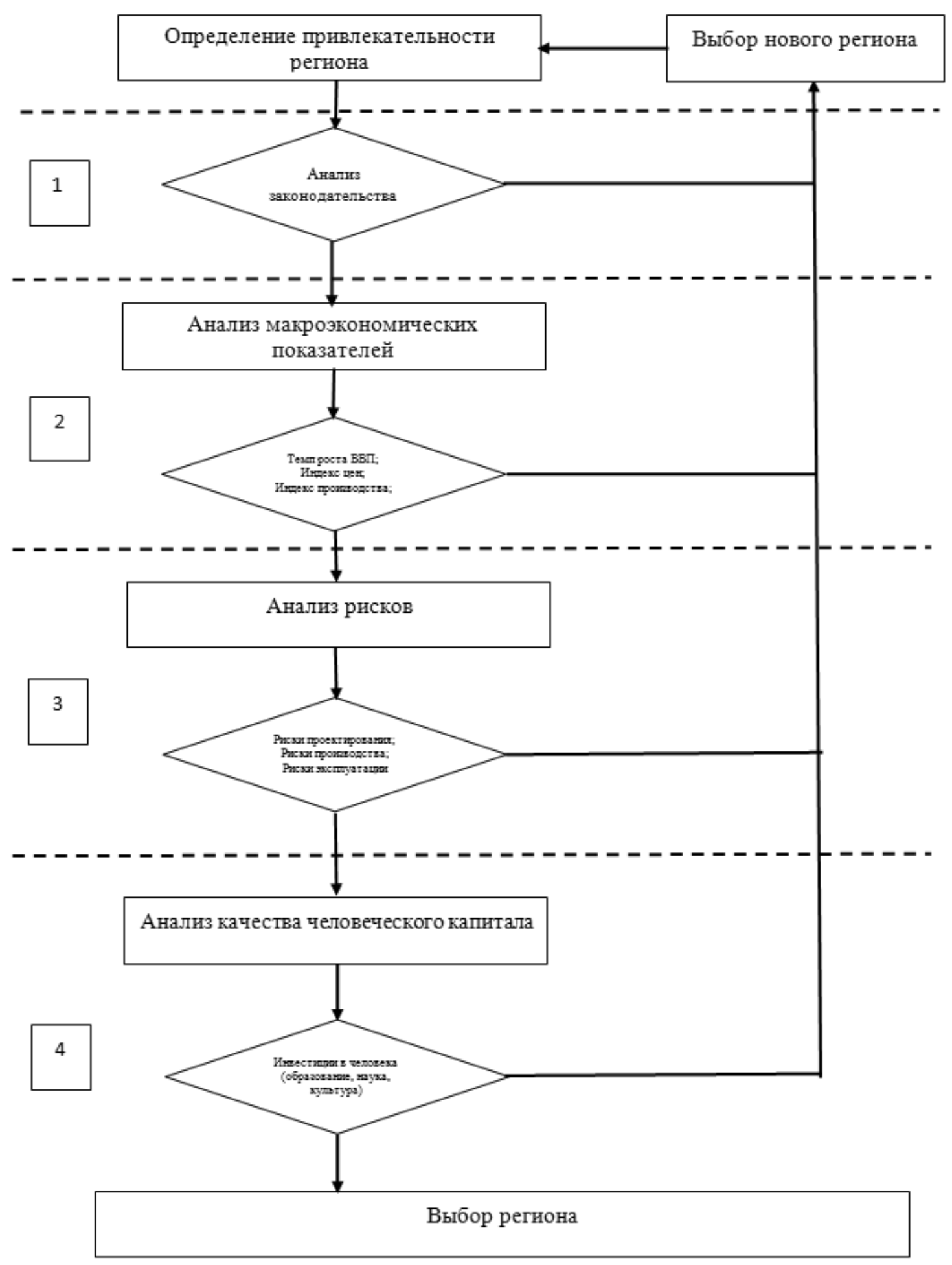

Рис. 2. Алгоритм оценки привлекательности макроэкономического субъекта 
робнее каждый из этапов.

Первый этап состоит из анализа законодательной базы для реализации проектов ГЧП, проводить данный анализ предлагается по следующей схеме (табл. 2, и табл. 3)

После проведения анализа регионального законодательства, предлагается занести результаты исследования в матрицу БКГ - анализа, модифицированную под данное исследование, где «Звезды» - лидеры по региональному законодательству, «Коровы» - привлекательны для с позиции законодательства по ГЧП, но не привлекательны для инвесторов, так как не развита законодательная база в этом направлении, «Дикие кошки» - слабое законодательство по ГЧП, но развитое по инвестиционной деятельности, привлекательны для внедрения проектов в форме ГЧП, так как существует возможность перехода в разряд звезд (при необходимом стимулировании законодательной базы), «Собаки» - не привлекательны для внедрения ГЧП.

Если проект проходит данный этап, необходимо приступать к следующему: анализ макроэкономических показателей. Для этого этапа выбраны показатели, которые в наибольшей степени характеризуют уровень экономического развития региона: (темп прироста ВВП (ВРП); индекс цен, индекс производства). Если по разработанным критериям, второй этап пройден, необходимо приступать к третьему.

На основе проведенного анализа существенных рисков с учетом данных количественного анализа выработана матрица последствий наступления рисков. Матрица сформирована относительно следующих независимых факторов (таблица 4).

Помимо количественных критериев, для сравнения моделей можно использовать качественные характеристики: анализ человеческого капитала - является по-

Составление рейтинга регионального законодательства о ГЧП

Таблица 2

\begin{tabular}{|c|c|c|}
\hline № $\Pi / п$ & Параметр & Шкала перевода \\
\hline 1 & $\begin{array}{l}\text { Анализ действующего законодательства, регла- } \\
\text { ментирующего сферу ГЧП }\end{array}$ & $\begin{array}{l}0 \text { баллов - отсутствует } \\
0,5 \text { баллов - проект закона ГЧП } \\
1 \text { балл - закон о ГЧП }\end{array}$ \\
\hline 2 & $\begin{array}{l}\text { Наличие права собственности частного партнера } \\
\text { на объект ГЧП }\end{array}$ & $\begin{array}{l}0 \text { баллов - нет права / не положений о праве } \\
\text { 0,25 баллов - два режима и право партнера не может быть бессрочным } \\
\text { 0,5 баллов - три режима и право партнера не может быть бессрочным } \\
\text { 0,75 баллов - два режима и право партнера может быть бессрочным } \\
1 \text { балл - три режима и право партнера может быть бессрочным }\end{array}$ \\
\hline 3 & Формы ГЧП по содержанию & $\begin{array}{l}0 \text { баллов - не прописаны } \\
\text { 0,25 баллов - прописаны только имущественные (узкий перечень) формы } \\
\text { 0,5 баллов - прописаны только имущественные (широкий перечень) формы } \\
\text { 0,75 баллов - прописаны имущественные и неимущественные (узкий перечень) формы } \\
1 \text { балл - прописаны имущественные и неимущественные (широкий перечень) формы }\end{array}$ \\
\hline 4 & Формы ГЧП по юридическому оформлению & $\begin{array}{l}0 \text { баллов - нет форм } \\
0,25 \text { баллов - } 1 \text { форма } \\
0,5 \text { баллов - } 2 \text { формы } \\
0,75 \text { баллов }-3 \text { формы } \\
1 \text { балл - } 4 \text { формы }\end{array}$ \\
\hline 5 & $\begin{array}{l}\text { Алгоритм принятия решения о заключении со- } \\
\text { глашения о ГЧП }\end{array}$ & $\begin{array}{l}0 \text { баллов - наличие специальной процедуры } \\
1 \text { балл - отсутствие специальной процедуры }\end{array}$ \\
\hline 6 & $\begin{array}{l}\text { Регламентированный порядок возмещения недо- } \\
\text { полученных доходов }\end{array}$ & $\begin{array}{l}0 \text { баллов - не закреплен } \\
1 \text { балл - закреплен }\end{array}$ \\
\hline 7 & Гарантия прав частного партнера & $\begin{array}{l}0 \text { баллов - гарантии не установлены } \\
0,5 \text { баллов - установлено от } 1 \text { до } 2 \text { типов гарантий } \\
1 \text { балл - установлено } 3 \text { и более типов гарантий }\end{array}$ \\
\hline 8 & $\begin{array}{l}\text { Наличие отрицательных решений ФАС России } \\
\text { касательного региональных соглашений о ГЧП }\end{array}$ & $\begin{array}{l}0 \text { баллов - отрицательные решения выявлены / отсутствие регионального законодатель- } \\
\text { ства о ГЧП } \\
1 \text { балл - негативная практика не выявлена }\end{array}$ \\
\hline
\end{tabular}


Таблица 3

Параметры сравнения законодательства об инвестиционной деятельности

\begin{tabular}{|c|c|c|}
\hline № $п / \Pi$ & Параметр & Шкала перевода \\
\hline 1 & $\begin{array}{l}\text { Анализ действующего законодательства субъекта в } \\
\text { сфере инвестиционной деятельности }\end{array}$ & $\begin{array}{l}0 \text { баллов - отсутствует } \\
1 \text { балл - закон принят }\end{array}$ \\
\hline 2 & $\begin{array}{l}\text { Оценка привлекательности объекта инвестиционной } \\
\text { деятельности }\end{array}$ & $\begin{array}{l}0 \text { баллов - не прописаны } \\
0,5 \text { баллов - перечень прописан } \\
1 \text { балл - перечень прописан и в составе перечня указание на объекты коммуналь- } \\
\text { ного хозяйства }\end{array}$ \\
\hline 3 & Наличие права собственности на объект у инвестора & $\begin{array}{l}0 \text { баллов - положение отсутствуют } \\
0,5 \text { баллов - возможность предусмотрена, но с ограничениями } \\
1 \text { балл - возможность предусмотрена }\end{array}$ \\
\hline 4 & Алгоритм заключения инвестиционного соглашения & $\begin{array}{l}0 \text { баллов - не установлен / положения отсутствуют } \\
0,5 \text { баллов - по результатам конкурса } \\
1 \text { балл - без проведения конкурса }\end{array}$ \\
\hline 5 & $\begin{array}{l}\text { Финансирование инвестиционной деятельности за счет } \\
\text { средств бюджета }\end{array}$ & $\begin{array}{l}0 \text { баллов - не предусмотрено / положения отсутствуют } \\
0,5 \text { баллов - финансирование реконструкции инфраструктуры до границы объекта } \\
1 \text { балл - предусмотрено }\end{array}$ \\
\hline 6 & $\begin{array}{l}\text { Нормативно-правовое закрепление гарантий прав } \\
\text { инвесторов }\end{array}$ & $\begin{array}{l}0 \text { баллов - не закреплено } \\
\text { 0,25 баллов - менее } 3 \text { типов гарантий } \\
\text { 0,5 баллов - 3-4 типа гарантий } \\
\text { 0,75 баллов - 5-6 типов гарантий } \\
1 \text { балл - свыше } 7 \text { типов гарантий }\end{array}$ \\
\hline 7 & Наличие форм поддержки инвестиционной & $\begin{array}{l}0 \text { баллов - не установлены } \\
0,25 \text { баллов - 1-4 типа форм } \\
0,5 \text { баллов - 5-7 типов форм } \\
\text { 0,75 баллов - 8-10 типов форм } \\
1 \text { балл - свыше } 10 \text { типов форм }\end{array}$ \\
\hline & & Итого балов \\
\hline
\end{tabular}

Таблица 4

Комплексный анализ последствий наступления рисков

\begin{tabular}{|c|c|c|}
\hline $\begin{array}{l}\text { Критерии оценки } \\
\text { последствий в0з- } \\
\text { никновения риска }\end{array}$ & Простой / линейный характер последствий & Сложносоставной / комплексный характер последствий \\
\hline \multirow{2}{*}{$\begin{array}{l}\text { Высокая } \\
\text { эластичность } \\
\text { ключевых по- } \\
\text { казателей }\end{array}$} & Существенные последствия & Крайне существенные последствия \\
\hline & $\begin{array}{l}\text { - Изменение процентных ставок по долговому финансированию } \\
\text { к моменту финансового закрытия } \\
\text { - Повышение сроков и затрат при сдаче объекта в эксплуатацию } \\
\text { и проведении пуско-наладочных работ; } \\
\text { - Невключение регулирующим органом отдельных затрат по } \\
\text { проекту в тариф; } \\
\text { - Несоответствие фактического объема и графика продаж } \\
\text { плановому; } \\
\text { - Индексация затрат, входящих в тариф, в объеме ниже требу- } \\
\text { емого }\end{array}$ & $\begin{array}{l}\text { - Банкротство монопотребителя; } \\
\text { - Банкротство концессионера; } \\
\text { - Незаключение договора о предоставлении субсидии на воз- } \\
\text { мещение недополученных доходов; } \\
\text { - Пересмотр плановых объемов финансирования в течение } \\
\text { бюджетного цикла; } \\
\text { - Несвоевременное финансирование капитальных затрат по } \\
\text { проекту со стороны инвестора; } \\
\text { - Сложности при утверждении объемов и сроков получения } \\
\text { компенсацией недополученных доходов; } \\
\text { - Утверждение регулирующим органом уровня затрат, входящих } \\
\text { в тариф, ниже запланированного }\end{array}$ \\
\hline \multirow{2}{*}{$\begin{array}{l}\text { Низкая эластич- } \\
\text { ность ключевых } \\
\text { показателей }\end{array}$} & Несущественные последствия & Существенные последствия \\
\hline & $\begin{array}{l}\text { - Перенос начала оказания услуг по вине потребителя; } \\
\text { - Ограничения, связанные с импортом оборудования и сырья; } \\
\text { - Доступность необходимой мощности объектов инженерной } \\
\text { инфраструктуры; } \\
\text { - Длительный период отвода земель; } \\
\text { - Сложность освобождения земельного участка от обременений; } \\
\text { Сложности при выкупе земельных участков; }\end{array}$ & $\begin{array}{l}\text { - Перенос начала оказания услуг по вине потребителя; } \\
\text { - Ограничения, связанные с импортом оборудования и сырья; } \\
\text { - Доступность необходимой мощности объектов инженерной } \\
\text { инфраструктуры; } \\
\text { - Длительный период отвода земель; } \\
\text { - Сложность освобождения земельного участка от обременений; } \\
\text { Сложности при выкупе земельных участков; }\end{array}$ \\
\hline
\end{tabular}


следним этапом оценки уровня привлекательности макроэкономического субъекта.

Данный анализ подразумевает под собой, оценку инвестиций в человеческий капитал: образование, науку, культуру.

\section{Выводы}

Таким образом, решение инвестора осуществлять свою деятельности в формате ГЧП - будет зависеть от ряда факторов:
1. Законодательство;
2. Макроэкономика;
3. Риски;
4. Человеческий капитал.

При реализации предложенной методики можно воспользоваться системой решения многокритериальной задачи на основе стохастических моделей.

\section{ЛИТЕРАТУРА}

1. Крекова М.М., Киселева Е.М., Красильников А.В. Влияние формирования цифровой экономики на развитие человеческих ресурсов // Современная наука: актуальные проблемы теории и практики. Серия «Экономика и право». -2017. -№ 12. -С. 41-43.

2. Зенкина Е.В. В поисках новых инструментов стимулирования экономического развития. // Инновации и инвестиции. 2020. № 5. С. 38-41

3. Халтурина Т.В., Охотников И.В., Сибирко И.В. Развитие региональной инфраструктуры: инвестиции институциональных инвесторов в реальный сектор экономики. // Russian Economic Bulletin. 2019. Т. 2. № 6. C. 57-61

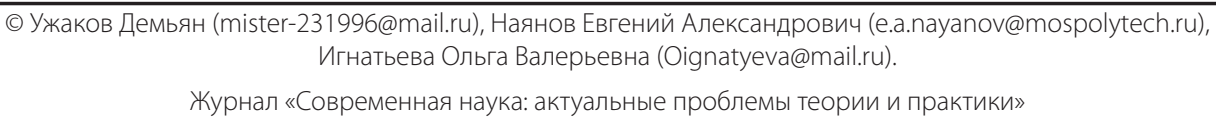

Журнал «Современная наука: актуальные проблемы теории и практики»

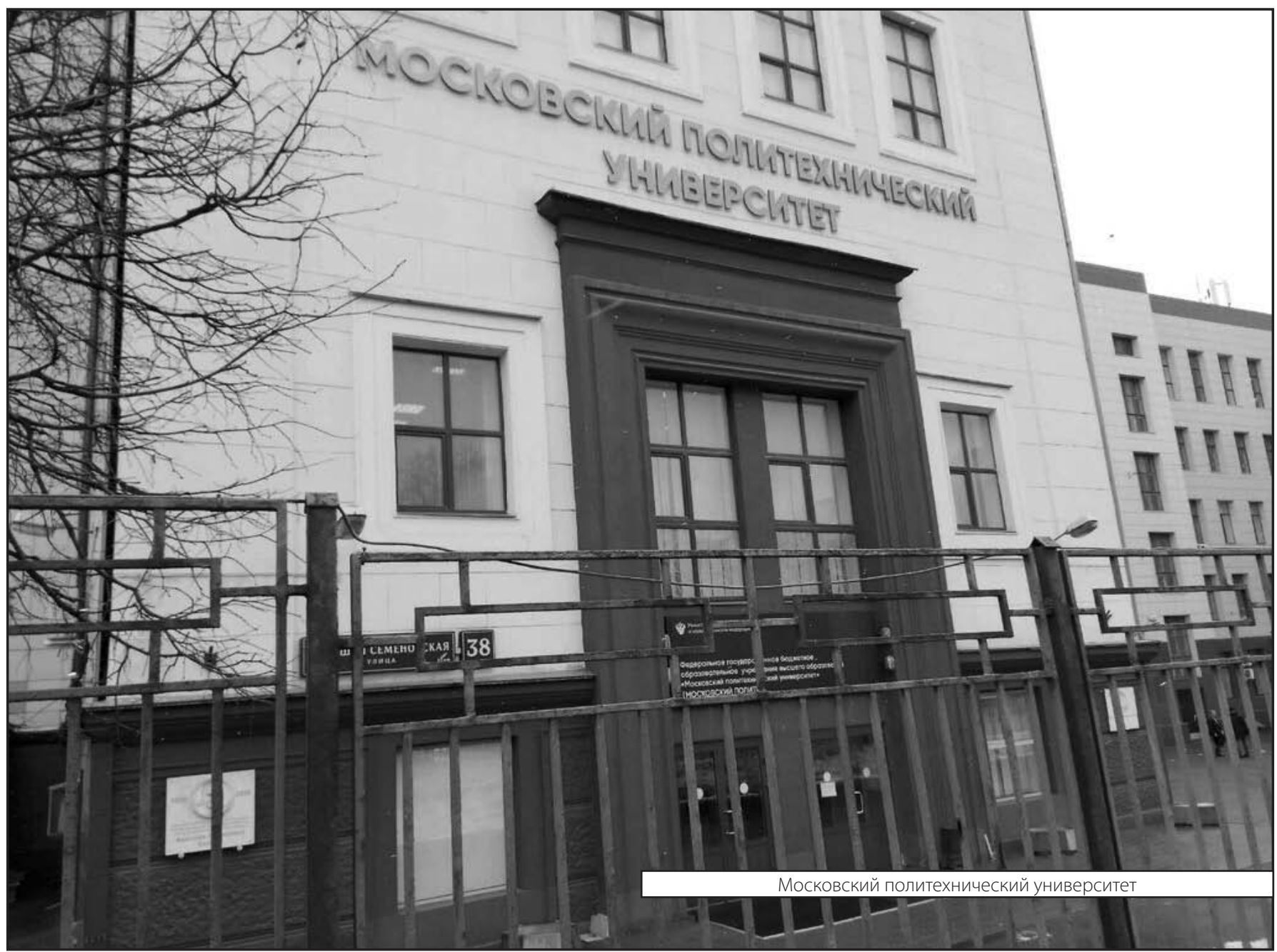

